Article

\title{
A Study of Multi-Pass Laser-Cladding 2205 Duplex Stainless Steel Coating: Microstructure, Electrochemical Corrosion Behavior, and Wear-Resistance Properties
}

\author{
Feifei Huang ${ }^{1,2, * \mathbb{C}}$, Erju Liu ${ }^{3,4}{ }^{\mathbb{C}}$, Yi Qin ${ }^{1}$, Qingrui Wang ${ }^{1}$, Ying Jin ${ }^{1,2}, * \mathbb{C}$, Lei Wen ${ }^{1,2}$ and Hai Chang ${ }^{1,2}$ \\ 1 National Center for Materials Service Safety, University of Science and Technology Beijing, \\ Beijing 100083, China; d202110524@xs.ustb.edu.cn (Y.Q.); b20190452@xs.ustb.edu.cn (Q.W.); \\ wenlei@ustb.edu.cn (L.W.); hchang@ustb.edu.cn (H.C.) \\ 2 Innovation Group of Marine Engineering Materials and Corrosion Control, Southern Marine Science and \\ Engineering Guangdong Laboratory, Zhuhai 519080, China \\ 3 Key Laboratory of Micro-Systems and Micro-Structures Manufacturing of Ministry of Education, \\ Harbin Institute of Technology, Harbin 150080, China; erju000@163.com \\ 4 School of Materials Science and Engineering, Harbin Institute of Technology, Harbin 150080, China \\ * Correspondence: feifeihuang@ustb.edu.cn (F.H.); yjin@ustb.edu.cn (Y.J.)
}

Citation: Huang, F.; Liu, E.; Qin, Y.; Wang, Q.; Jin, Y.; Wen, L.; Chang, H.

A Study of Multi-Pass

Laser-Cladding 2205 Duplex

Stainless Steel Coating:

Microstructure, Electrochemical

Corrosion Behavior, and

Wear-Resistance Properties. Coatings 2022, 12, 229. https://doi.org/

$10.3390 /$ coatings12020229

Academic Editor:

Emanuele Galvanetto

Received: 19 January 2022

Accepted: 3 February 2022

Published: 10 February 2022

Publisher's Note: MDPI stays neutral with regard to jurisdictional claims in published maps and institutional affiliations.

Copyright: (C) 2022 by the authors. Licensee MDPI, Basel, Switzerland. This article is an open access article distributed under the terms and conditions of the Creative Commons Attribution (CC BY) license (https:// creativecommons.org/licenses/by/ $4.0 /)$.

\begin{abstract}
By applying 2205 duplex stainless steel powders to repair and improve carbon steel, multipass laser-cladding tests were conducted on Q235 carbon steel surfaces with different laser powers in the range of $1.9 \sim 2.5 \mathrm{~kW}$ in order to evaluate the performance of the laser-cladding layers. The phase composition, macro- and microstructure, electrochemical corrosion resistance, friction, and wear resistance of the laser-cladding layers were investigated. Macroscopic observation identified no obvious cracks. The phases that made up the multi-pass laser-cladding layers were $\gamma$-Fe and $\alpha$-Fe. Owing to the optimal laser power at $2.3 \mathrm{~kW}$, a large number of equiaxed crystals and a small number of cellular crystals made up the microstructure of the prepared laser-cladding layer, which contributed to its good corrosion resistance. The wear resistance of the multi-pass laser-cladding layer and the carbon steel was also studied. A combined action of adhesive wear and abrasive wear, accompanied by oxidative wear, was determined through observation of pits and furrows on the friction surface of the multi-pass laser-cladding layer, while a typical mechanism of abrasive wear was confirmed by checking the friction surface of the carbon steel.
\end{abstract}

Keywords: laser cladding; 2205 duplex stainless steel laser-cladding layer; Q235 carbon steel; electrochemical resistance; wear resistance

\section{Introduction}

Stainless steels, nickel-base alloys, and cobalt-base alloys are widely used in oil and gas, chemical, marine, aerospace, and nuclear power industries, owing to their excellent mechanical properties and corrosion-resistance characteristics [1-6]. Enrichment of stainless steel coatings with chromium, nickel, and molybdenum prepared on carbon steel can broaden the applications of carbon steel in corrosive environments while reducing comprehensive costs due to the passive film formed on the coatings.

The laser-cladding technique can offer a very promising way to restore the geometry and structural integrity of carbon steel components that have suffered from corrosion cracking and wear damage. The above feature of laser cladding makes it one of the most promising surface-modification techniques. A laser-cladding layer with good metallurgical bonding with the substrate is formed by using a high-energy density laser beam to rapidly melt metal powders [7]. The surface performance of materials is improved by means of imparting a laser-cladding layer with extremely high wear and corrosion resistances. Compared with other surface-modification techniques, such as spray coating, electroplating, and vapor deposition, etc., laser cladding requires a low dilution and can produce a layer 
with fine microstructure and good adhesion to the substrate, leading to its wide use in the aerospace, mold, and electrical industries, among others [8-10].

Studying the geometrical characteristics of laser-cladding layers and the parameters of the laser-cladding process is beneficial, as it can allow for precise control of their shapes and microstructures. Extensive studies have been carried out to investigate the geometrical features and properties of stainless steel laser-cladding layers, as well as the influences of parameters of the laser-cladding process.

Cheikh et al. prepared 316L stainless steel laser-cladding layers on low-carbon steel. Different velocities and laser-shift distances between two successive layers were used to build laser-cladding walls. A linear relationship was observed between the wall height and the number of layers (for each condition, 1, 3, 5, and 10 layer walls are analyzed). The quality of the fabricated walls related to the process parameters. A low laser shift combined with a high laser speed seemed to be the better choice to optimize the wall quality and the time of fabrication based on the experimental results [11]. Although the laser-cladding parameters were determined for preparation of the walls, the performance of the laser-cladding walls was unclear.

The metallurgical and geometrical characteristics of the 316L stainless steel cladding layers deposited onto the mild steel substrate at different locations along the length of the track were studied by Rahman Rashid et al., and the results showed a remarkable change in the thickness of the cladded layer along the length direction, with the initial thickness $(0-15 \mathrm{~mm})$ of the cladded layer being much thinner than the final thickness (75-90 mm) [12]. Besides, end-of-track cracking during the laser-cladding process was also observed, pointing out the demand for further study to mitigate end-of-track cracking in order to refine the laser-cladding process. J. Liu et al. [13] prepared AerMet100 steel coating on $300 \mathrm{M}$ steel by multi-pass laser-cladding technique. AerMet100 clad coating has a dilution ratio of $11 \%$, which is caused by the remelting of $300 \mathrm{M}$ steel substrate. Microstructures in the clad layer consist of tempered martensite, retained austenite, and fine carbides. The low hardness of thick-plate bainite and large, brittle, blocky retained austenite were observed in the microstructure, which dramatically lowered the strength and ductility of AerMet100/300 M ultra-high-strength steel.

P. Xu et al. used a multi-pass laser-cladding technique to coat a 304 stainless-steelcladded layer on 45 carbon steel. They observed that the microstructure of the prepared layer gradually transformed from coarse, columnar, dendritic grains at the interface to dense and fine equiaxed grains at the top area of the cladded layer; therefore, the prepared layer can provide better corrosion resistance than AISI 304 stainless steel $/ \mathrm{Al}_{2} \mathrm{O}_{3}$ composite coatings [14]. However, higher hardness and corrosion resistance cannot be achieved simultaneously. J. Wen et al. [15] adjusted the technological factors, including the power feed rate, laser power, and scanning speed, aiming to fabricate laser-cladding coatings of the self-made, dual-phase stainless steel powders on the as-hot-rolled 2205 dual-phase stainless steel. Although the corrosion resistance of the laser-cladding layer declined to some extent, the bonding strengths between the laser-cladding layer and the substrate were satisfactory. Necessary adjustments to the process parameters need to be made to improve corrosion resistance.

Laser-cladding composite coatings on bare metal have attracted the attention of many researchers. For example, Ni-based single- and graded-composite coatings of Ni35 + tungsten carbide (WC), Ni35 + original sialon powders (OSP), and Ni35 + WC + OSP were prepared by laser cladding on 45 steel substrates by Y. Sui et al. [16]. The hardness and wear resistance of the graded coatings were better than those of the single-composite coatings, except the Ni35 + WC + OSP composite coatings, which also had significantly higher hardness and wear resistance. The addition of $\mathrm{Ru}, \mathrm{Mo}, \mathrm{Cr}_{3} \mathrm{C}_{2}$, and $\mathrm{La}_{2} \mathrm{O}_{3}$ in laser-cladding powders can also help to obtain more uniform and fine grains and eventually improve the comprehensive properties of the prepared layers [17-20].

Numerous studies have been carried out on manufacturing processes, including welding, casting, and rolling processes of duplex stainless steel, exhibiting better corrosion 
resistance and toughness compared to pure ferritic stainless steels [21-23]. However, research on laser-cladding manufacturing of duplex stainless steels is still limited. Most existing studies only evaluate the relationship between laser-cladding process parameters and structure but ignore properties such as wear, corrosion resistance, etc. Moreover, no further research has been carried out with the aim of evaluating the relationship between laser-cladding parameters and the structure and performance of the laser-cladding layers. Our previous study focused on relationships between laser powers and geometrical characteristics, microstructure, microhardness, and corrosion resistance of single-pass lasercladded 2205 duplex stainless steel layers [24]. In order to obtain large-area laser-cladding layers and promote their application in practical environments, further related multi-pass laser-cladding studies urgently need to be carried out. In this study, multi-pass 2205 duplex stainless steel (2205DSS) laser-cladding layers were prepared on the surface of Q235 carbon steel at laser powers in the range of 1.9-2.5 kW. Insight into the relationships between laser power and phase composition, microstructure, and corrosion resistance of the lasercladding layers are analyzed and discussed through a systematic study. Consequently, an optimal laser power for fabricating 2205DSS laser-cladding layers on Q235 carbon steel is proposed. Furthermore, the difference in friction and wear behavior between the optimal laser-cladding layer and Q235 carbon steel is clarified.

\section{Materials and Methods}

\subsection{Sample Preparation}

Q235 carbon steel and 2205 duplex stainless steel (2205DSS) powder were used as the substrate material and the laser cladding material in the experiment, respectively. The chemical compositions of the two materials are shown in Table 1. Before the experiment, a Q235 carbon steel sheet was cut to dimensions of $150 \mathrm{~mm} \times 100 \mathrm{~mm} \times 10 \mathrm{~mm}$. The surface of the substrate material was polished with sandpaper, down to 2000\#, to remove the oxide film and ensure the smoothness of the substrate material, which was then cleaned with alcohol to remove oil from the sample surface and finally placed in a drying oven.

Table 1. Nominal chemical compositions (wt.\%) of Q235 carbon steel and 2205DSS power.

\begin{tabular}{ccccccccccc}
\hline Elements & $\mathbf{C}$ & $\mathbf{N}$ & $\mathbf{S}$ & $\mathbf{P}$ & $\mathbf{S i}$ & $\mathbf{C r}$ & $\mathbf{N i}$ & $\mathbf{M o}$ & $\mathbf{M n}$ & $\mathbf{C u}$ \\
\hline Q235 carbon steel & 0.20 & - & $\leq 0.05$ & $\leq 0.045$ & $\leq 0.3$ & - & - & - & 0.4 & - \\
2205 DSS powder & 0.015 & $\leq 0.045$ & $\leq 0.05$ & $\leq 0.045$ & 1.22 & 22.76 & 6.2 & 3.3 & 1.5 & $\leq 0.045$ \\
\hline
\end{tabular}

The 2205DSS powder was bought from AMC Powders Corp. and consisted of particles of long strips with sizes in the range of 100-200 $\mu \mathrm{m}$ [24]. The powder shape and relative microstructure demonstrations of the Q235 carbon steel were described in our previous work [24]. The 2205DSS powder needed to be dried in a vacuum furnace at $70{ }^{\circ} \mathrm{C}$ for $5 \mathrm{~h}$ prior to the laser-cladding process.

A laser-cladding system made up of a TruDiode 4006 laser with a wavelength of $1070 \mathrm{~nm}$ and a coaxial powder-feeding system $(5 \mathrm{~mm}$ round spot, Trumpf, Stuttgart, Germany) was used to conduct the laser-cladding experiment. The laser head, powder-feeding nozzle, and shielding gas nozzle moved together along a straight line on top of the substrate during the laser-cladding process. The powder fed into the molten pool at a feed rate of $15 \mathrm{~g} / \mathrm{min}$ was protected with a high-purity argon-shielding gas covering the molten pool at a flow rate of about $10 \mathrm{~L} / \mathrm{min}$ from oxidation. In all cases, the laser-cladding parameters were: laser powers of 1.9, 2.1, 2.3, and $2.5 \mathrm{~kW}$; a laser-spot diameter of $5 \mathrm{~mm}$; a scanning speed of $5 \mathrm{~mm} / \mathrm{s}$; and a lap rate of $40 \%$. 


\subsection{Characterizations of the Samples}

\subsubsection{Surface Macro/Micromorphology and Phase Compositions}

After the laser-cladding process was completed, the macroscopic morphologies of cladding layers prepared under various technological parameters were observed by a digital camera.

The phase compositions of the multi-pass laser-cladding layers prepared under different laser powers were analyzed by an X-ray diffractometer (XRD, Rigaku Smartlab, Tokyo, Japan) with a $2 \theta$ scan range of 20-100. Jade software and PDF cards were used to identify and calibrate the peaks.

The sheet after laser cladding was then cut into samples of $5 \mathrm{~mm} \times 8 \mathrm{~mm} \times 10 \mathrm{~mm}$. The circular arc surface of the cladding sample was then ground into a plane. Electrolytic erosion was carried out on the polished samples in $10 \%$ oxalic acid solution at a voltage of $10 \mathrm{~V}$ for $30 \mathrm{~s}$ at room temperature. The sample surface was then rinsed with deionized water and dried using a cool air breeze, at which point the microstructure of the cladding layer was observed by optical microscopy (OM, Olympus X53, Tokyo, Japan).

A scanning electron microscope (SEM, Zeiss SIGMA 500, Jena, Germany) equipped with an energy-dispersive spectrometer (EDS, Zeiss, Jena, Germany) was employed to obtain morphological and elemental information about the multi-pass laser-cladding layers and Q235 carbon steel after friction and wear processes.

\subsubsection{Electrochemical Tests}

The arc surface of the cladding sample was ground flat and sealed with epoxy resin and ethylenediamine. All electrochemical tests were carried out in $3.5 \mathrm{wt} . \% \mathrm{NaCl}$ solution using a three-electrode system with platinum as the counter electrode, an $\mathrm{Ag} / \mathrm{AgCl}$ electrode as reference electrode, and the prepared laser-cladding layer sample as the working electrode.

The open-circuit potentials (OCPs) of the prepared laser-cladding layer samples were tested by Gamry instruments (Gamry Reference 600, Gamry Instruments, Philadelphia, PA, USA). Electrochemical impedance spectroscopy (EIS) was then performed with a scanning frequency range of $0.01 \mathrm{~Hz}-100 \mathrm{kHz}$ and an AC amplitude of $\pm 10 \mathrm{mV}$. Fitting of the obtained impedance data was carried out through ZsimpWin software (version 3.50, Princeton Applied Research). Finally, potentiodynamic polarization was carried out by potentiostat with a scanning rate of $0.5 \mathrm{mV} / \mathrm{s}$ and a scanning range of $-0.4-0.8 \mathrm{~V}$ (vs. OCP).

\subsubsection{Friction and Wear Tests}

Wear-resistance tests were performed on the Q235 carbon steel and laser-cladding sample prepared at $2.3 \mathrm{~kW}$ using a block-on-ring-type tribotester, i.e., an MRH-3 highspeed ring-block wear tester (Jinanshunmao Test Instruments Co. Ltd., Jinan, China). In the test, the Q235 carbon steel and the laser-cladding sample with dimensions of $12.35 \mathrm{~mm} \times 12.35 \mathrm{~mm} \times 19.00 \mathrm{~mm}$ were pressed against a standard GCr15 bearing steel ring with a diameter of $49.24 \mathrm{~mm}$ and a width of $13.00 \mathrm{~mm}$ under a constant load of $50 \mathrm{~N}$ at a speed of $200 \mathrm{r} / \mathrm{min}$ for $1800 \mathrm{~s}$ in dry-friction mode at room temperature. In the meantime, the friction coefficient data were recorded. Before the experiment, the Q235 steel, the laser-cladding sample, and the standard GCr15 bearing steel ring were ultrasonically cleaned successively in petroleum ether and ethanol for $5 \mathrm{~min}$ and then blow-dried. The Q235 carbon steel and the laser-cladding sample were weighed by an analytical balance with an accuracy of $0.01 \mathrm{mg}$. After the wear-resistance test, the Q235 carbon steel and the laser-cladding sample were ultrasonically cleaned and weighed according to the same procedure described above. Therefore, the weight loss as a result of abrasion of the Q235 steel and the laser-cladding sample can be calculated.

\section{Results and Discussion}

\subsection{Surface Macromorphology Analysis of the Laser-Cladding Layer}

The macroscopic morphologies of the laser-cladding layers prepared at different laser powers ranging from 1.9-2.5 kW are shown in Figure 1. No obvious cracks are observed in 
the four kinds of samples, illustrating metallic luster and good surface-layer quality. The surface morphologies of the beginning of the laser-cladding layers are thin and flat in all cases, which is mainly caused by insufficient laser energy at the starting point.

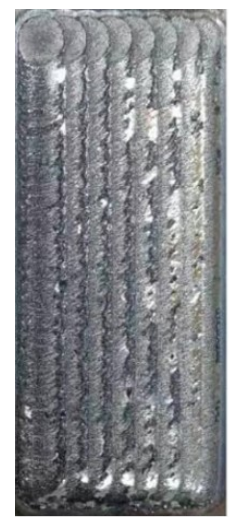

(a)

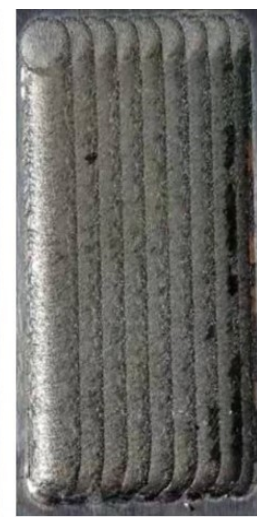

(b)

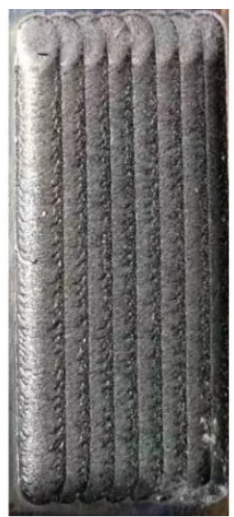

(c)

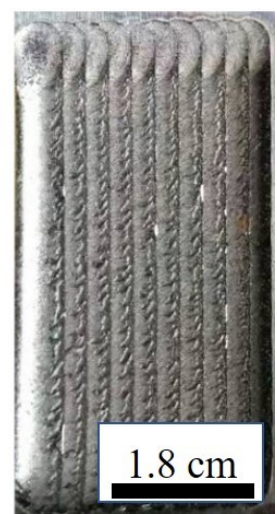

(d)

Figure 1. Macromorphologies of multi-pass laser-cladding layers prepared at different laser powers: (a) $\mathrm{P}=1.9 \mathrm{~kW}$; (b) $\mathrm{P}=2.1 \mathrm{~kW}$; (c) $\mathrm{P}=2.3 \mathrm{~kW}$; (d) $\mathrm{P}=2.5 \mathrm{~kW}$.

Figure $2 \mathrm{a}, \mathrm{b}$ are experimental photos and a schematic of the laser-cladding process. Figure $2 \mathrm{c}$ is a cross-section physical diagram of a multi-pass laser-cladding layer in which $\mathrm{Y}$ is the direction of multi-pass laser cladding, $\mathrm{Z}$ is the vertical direction of the substrate, and $X$ is the direction of single-pass laser cladding. It can be seen that the surface of the laser-cladding layer has regular fluctuations due to overlapping. When evaluating the performance of multi-pass cladding layers, the curved surface should be polished into a plane (yellow line in Figure 2c).

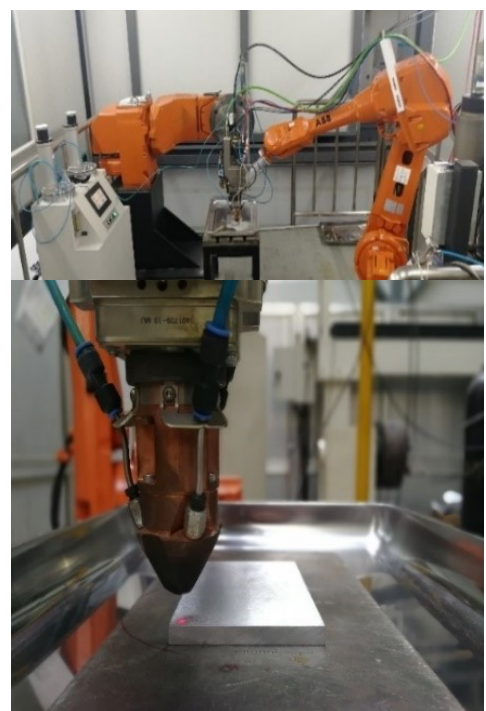

(a)

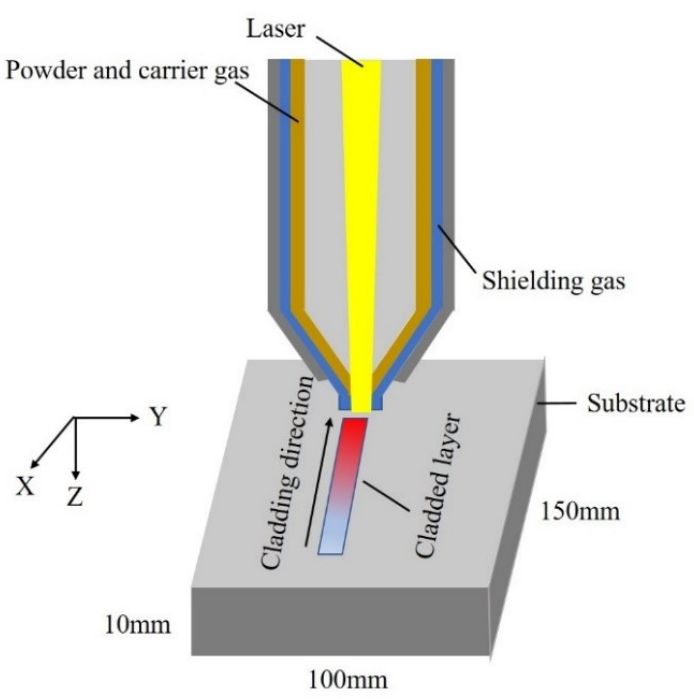

(b)

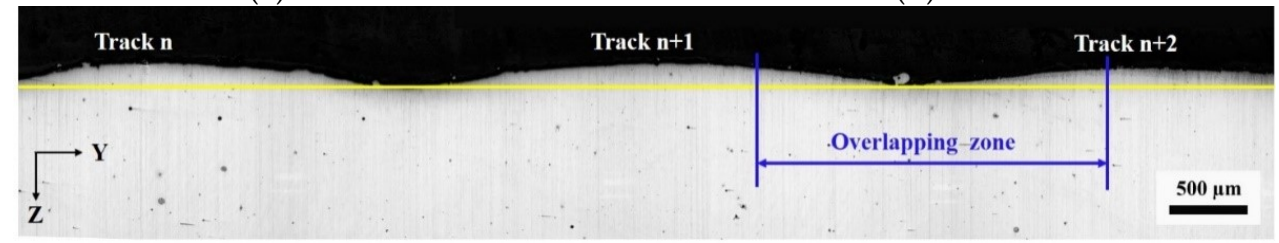

(c)

Figure 2. Experimental photos (a) schematic (b) of the laser-cladding process, and cross section morphology of the multi-pass laser-cladding layer (c). 


\subsection{Phase-Composition Analysis of the Laser-Cladding Layers}

XRD patterns of the multi-pass laser-cladding layers prepared at different laser powers are illustrated in Figure 3. It can be seen from the figure that the laser-cladding layers prepared at different laser powers are mainly composed of $\gamma$-Fe phases with strong diffraction peaks on the (111), (200), and (311) crystal planes and $\alpha$-Fe phases with strong diffraction peaks on the (110) crystal plane. The diffraction peaks of the (200) and (211) planes indicating $\alpha$-Fe phases and the (220) plane indicating $\gamma$-Fe phases are weak. The diffraction peak of the (110) crystal plane of the laser-cladding layer prepared at $1.9 \mathrm{~kW}$ is weak, indicating low $\alpha$-Fe content in the corresponding laser-cladding layer. With an increase in laser power, the diffraction peak of the (110) crystal plane gradually strengthens, and the $\alpha$-Fe content in the cladding layer increases, which implies that the $\gamma$-Fe phase partially transforms into an $\alpha$-Fe phase with an increase in laser input energy.

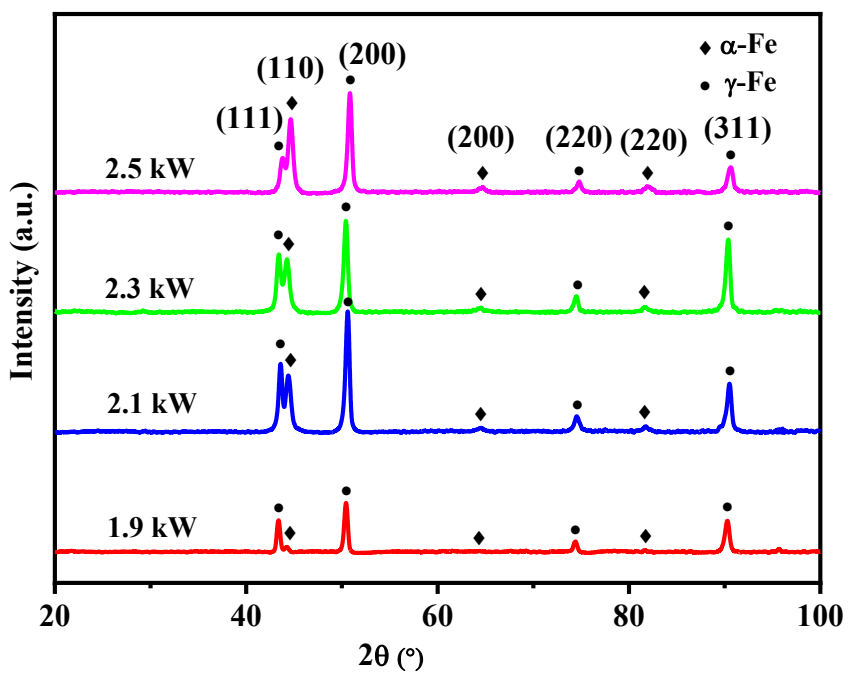

Figure 3. XRD pattern of multi-pass laser-cladding layers.

The main peak positions of the diffraction peaks obtained from the laser-cladding layers prepared at different laser powers are summarized and listed in Table 2. Peak positions of the laser-cladding layer prepared at $2.3 \mathrm{~kW}$ shift to smaller $2 \theta$ direction compared with those of the layers prepared at 2.1 and $2.5 \mathrm{~kW}$, indicating an increase in interplanar spacing in the microstructure.

Table 2. Diffraction-peak positions obtained from the laser-cladding layers prepared at different laser powers.

\begin{tabular}{ccccccc}
\hline \multirow{2}{*}{ Laser Powers/kW } & \multicolumn{3}{c}{ Peak Positions of $\boldsymbol{\gamma}$-Fe } & \multicolumn{3}{c}{ Peak Positions of $\boldsymbol{\alpha}$-Fe } \\
\cline { 2 - 7 } & $\mathbf{( 1 1 1 )}$ & $\mathbf{( 2 0 0 )}$ & $\mathbf{( 3 1 1 )}$ & $\mathbf{( 1 1 0 )}$ & $\mathbf{( 2 0 0 )}$ & $\mathbf{( 2 2 0 )}$ \\
\hline 1.9 & 43.4 & 50.47 & 90.34 & 44.3 & - & - \\
2.1 & 43.6 & 50.48 & 90.55 & 44.4 & 64.56 & 81.8 \\
2.3 & 43.4 & 50.42 & 90.34 & 44.2 & 64.51 & 81.75 \\
2.5 & 43.7 & 50.86 & 90.7 & 44.7 & 64.78 & 82.01 \\
\hline
\end{tabular}

\subsection{Surface Microstructure Analysis of the Laser-Cladding Layers}

Figure 4 illustrates the surface microstructures of the laser-cladding layers. $X$ shows the direction of single-pass laser cladding, and $Y$ is the direction of multi-pass cladding. It can be seen that there are interfaces formed by overlapping between each track, and the microstructure of the lower part of the lap interface (region A of track $n$ ) and that of the upper part (region $\mathrm{B}$ of track $n+1$ ) are obviously different. 

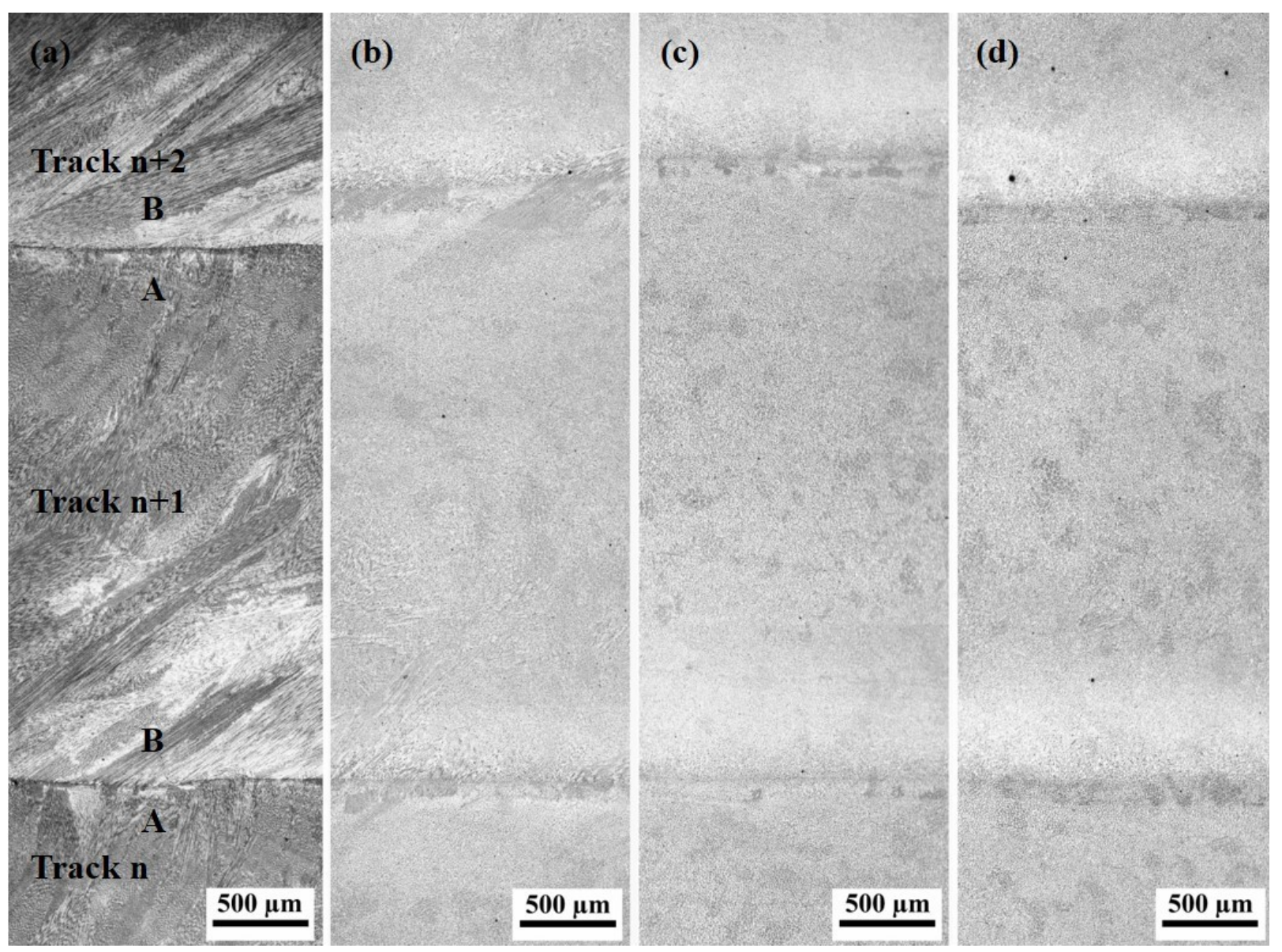

Figure 4. Microstructure of the multi-pass laser-cladding layers prepared at different laser powers: (a) $\mathrm{P}=1.9 \mathrm{~kW}$; (b) $\mathrm{P}=2.1 \mathrm{~kW}$; (c) $\mathrm{P}=2.3 \mathrm{~kW}$; (d) $\mathrm{P}=2.5 \mathrm{~kW}$.

The solidification structure of zone B in track $n+1$ (Figure 4a) formed at a laser power of $1.9 \mathrm{~kW}$ is columnar dendrites, the direction of which is at a certain included angle with the interface. A bright white area in zone B is also observed. This phenomenon is consistent with the microstructures obtained from the single-pass laser-cladding layer under low laser power [24]. The solidification structure in region A is equiaxed crystal, basically without directionality.

During the multi-pass laser-cladding process, the laser-cladding layer track $n$ solidifies earlier than track $n+1$, which is the main heat dissipation channel. According to solidification theory, the stabilizing factor $(\mathrm{G} / \mathrm{R})$ between the solid-liquid interface determines the morphology of the solidification microstructure, where $G$ represents the temperature gradient, and $R$ is the solidification rate [25]. Therefore, because of the high G/R value of the metal liquid near the interface, the melt-metal liquid in track $n+1$ solidifies and forms directional columnar dendrite structures.

The difference in microstructure between the upper and lower regions of the interface becomes minimized when laser power is increased to $2.1 \mathrm{~kW}$ (Figure $4 \mathrm{~b}$ ), and only a few columnar dendritic crystals can be found. Although the previously solidified cladding layer can still be used as the heat-dissipation channel of the following cladding layer, this effect is weakened. Due to the increase in laser power, the temperature of the laser-cladding layer that was solidified first is still very high when the following cladding layer solidifies, so the temperature gradient of the melt-metal liquid at the interface front in the next cladding layer is not as large as that under low laser power, leading to the small number of columnar dendritic crystals. When the laser power increases to 2.3 and $2.5 \mathrm{~kW}$, the microstructure of the upper and lower regions of the interface is almost the same. 
Observation of the cross-section morphology of the single-pass laser-cladding layer reveals that the solidification microstructure of the laser-cladding layer is mainly affected by $\mathrm{G} / \mathrm{R}$ in the $\mathrm{Z}$ direction (vertical direction of the carbon steel substrate). On the other hand, the solidified microstructure of the surface of the multi-pass cladding layer is mainly affected by $G / R$ in the $Y$ direction. This difference can be explained by the fact that the cladding layer that solidified first acts as a heat-dissipation channel, like the carbon steel substrate; however, this effect only works at low laser power.

In order to further explore the microstructure of the lap interface, the surface microstructures of the lap area of the multi-pass laser-cladding layers prepared under the selected laser powers are shown in Figure 5. The solidification structure in the upper area of the interface (region B of track $n+1$ ) formed between two adjacent tracks at a laser power of $1.9 \mathrm{~kW}$ is columnar and dendritic, whereas that in the lower region of the interface (region A of track $n$ ) is composed of fine columnar crystals and a few equiaxed crystals. The interface between two neighboring tracks is quite obvious, and the solidified sequence can be clearly separated from the solidification microstructure after laser cladding.
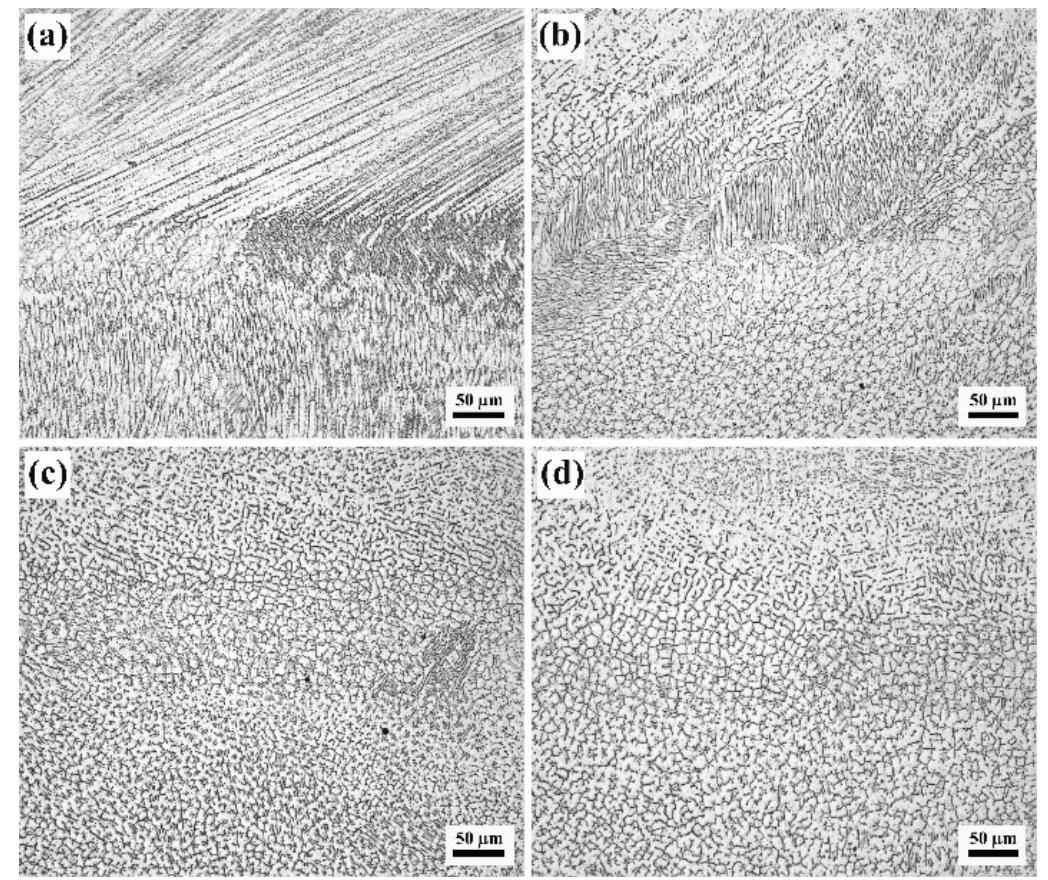

Figure 5. Microstructure of the overlap area of multi-pass laser-cladding surfaces prepared at different laser powers: (a) $\mathrm{P}=1.9 \mathrm{~kW}$; (b) $\mathrm{P}=2.1 \mathrm{~kW}$; (c) $\mathrm{P}=2.3 \mathrm{~kW}$; (d) $\mathrm{P}=2.5 \mathrm{~kW}$.

In the case of a laser power of $2.1 \mathrm{~kW}$, the size of columnar dendrites in the upper part of the interface (region B of track $n+1$ ) obviously decreases, and equiaxed crystals in the solidification microstructure can be identified in the lower region of the interface (region A of track $n$ ). A number of cellular crystals the area around the interface can also be recognized. At $2.3 \mathrm{~kW}$, the difference between the upper and lower regions of the interface further decreases, and no columnar crystals can be observed at all. The solidification structure of the interface region consists of a large number of equiaxed crystals and a small number of cellular crystals. At $2.5 \mathrm{~kW}$, the solidification microstructure of the interface region is composed entirely equiaxed crystal.

According to Figures 4 and 5, the surface microstructures of the multi-pass lasercladding layers obtained at laser powers of 2.3 and $2.5 \mathrm{~kW}$ are uniform, with little difference between the microstructures at each laser power. Air holes are inevitable in the lasercladding process, but appropriate process parameters can reduce the number of air holes in the cladding layer. By observing the pores in the surface microstructure of the multi-pass laser-cladding layer, it is found that the pores of the multi-pass cladding layers show a 
certain regularity, i.e., the pores within laser-cladding layer $n+1$ gradually decrease along the $\mathrm{Y}$ direction. In other words, the pores are mainly distributed in region B of track $n+1$.

Figure 6 shows the multi-pass laser-cladding layer prepared at a laser power of $2.5 \mathrm{~kW}$, with a large number of pores in the upper area of the interface (region B of track $n+1$ ). The reason for this phenomenon is that zone $\mathrm{B}$ of track $n+1$, which is adjacent to the previously solidified cladding layer, track $n$, makes its cooling rate faster so that the gas has no time to exhaust during the solidification process, resulting in pores in the microstructure. In addition, it is found that there are more pores in the cladding layer prepared at high laser power, which is due to the serious evaporation phenomenon of the metal powder at the high-laser-power level contributing to an increase in generated gas, and eventually, the number of pores in the laser-cladding layer increases. Comprehensively considering the microstructure, composition and the number of pores within the multi-pass laser cladding layer, the one prepared with a laser power of $2.3 \mathrm{~kW}$ is preferable.

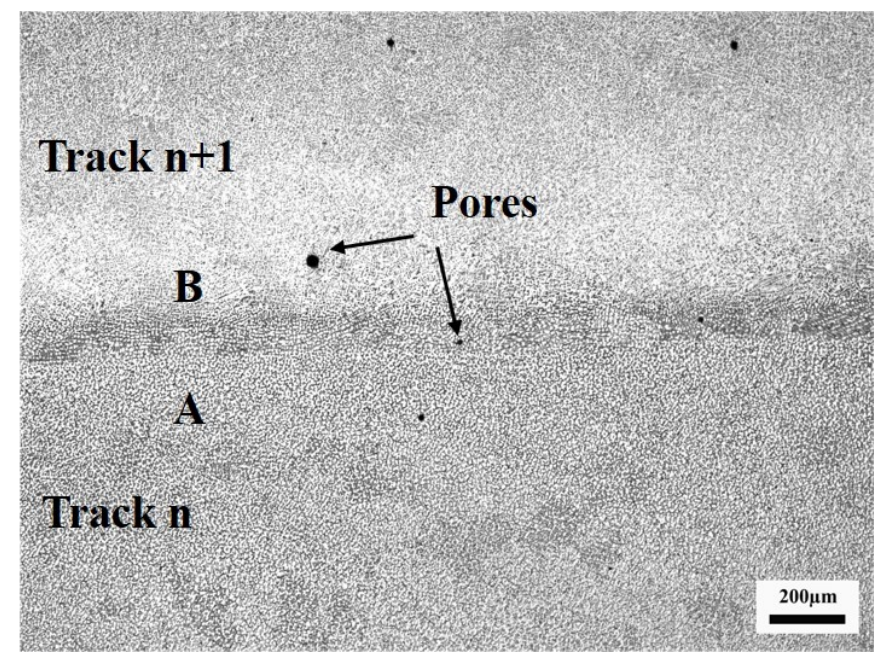

Figure 6. Magnification of the overlap area of the laser-cladding surface prepared at $2.5 \mathrm{~kW}$.

\subsection{Electrochemical Analysis of The Laser-Cladding Layer}

This section evaluates the corrosion resistance of the laser-cladding layers prepared at different laser powers. The open-circuit potential (OCP) curves, i.e., potential-time dependance curves, and the potentiodynamic polarization (PDP) curves in $3.5 \mathrm{wt} . \% \mathrm{NaCl}$ solution are illustrated in Figures 7 and 8, respectively. The OCP of the multi-pass lasercladding layer prepared at $2.3 \mathrm{~kW}$ is the most positive (about $-138 \mathrm{mV}$ ), followed by the multi-pass laser-cladding layers prepared at $2.1 \mathrm{~kW}(-179 \mathrm{mV})$ and $2.5 \mathrm{~kW}(-198 \mathrm{mV})$. The multi-pass laser-cladding layer prepared at $1.9 \mathrm{~kW}$ is the most negative $(-224 \mathrm{mV})$. This indicates that the corrosion tendency of the multi-pass laser-cladding layer prepared at $2.3 \mathrm{~kW}$ is the smallest among the fabricated samples, while that prepared at $1.9 \mathrm{~kW}$ corrodes most seriously under the same conditions.

The data of potentiodynamic polarization curves obtained by Tafel fitting are shown in Table 3. With the increase in laser power, the corrosion potential $\left(E_{c o r r}\right)$ first increases and then decreases, and the corrosion-current density $\left(I_{\text {corr }}\right)$ exhibits the opposite trend. The multi-pass cladding layer prepared at $2.3 \mathrm{~kW}$ has a maximum corrosion potential of $-193.2 \mathrm{mV}$ and a minimum corrosion-current density of $0.119 \mu \mathrm{A} / \mathrm{cm}^{2}$. Pitting potential $\left(E_{b}\right)$, also known as the breaking point, is an important index to evaluate the corrosion resistance of passivated metals. As can be seen from Table 3, the pitting potential of the multi-pass laser-cladding layer at $2.1 \mathrm{~kW}$ is the highest $(424.8 \mathrm{mV})$-slightly higher than that prepared at $2.3 \mathrm{~kW}(394.2 \mathrm{mV})$, followed by the multi-pass laser-cladding layer prepared at $1.9 \mathrm{~kW}(242.7 \mathrm{mV})$, while that prepared at $2.5 \mathrm{~kW}$ has the lowest pitting potential, at $204.0 \mathrm{mV}$. In addition to pitting potential, the passive current density $\left(i_{p}^{\prime}\right)$ can also be used to evaluate the corrosion resistance of passivated metals. The smaller the 
passive current, the better the corrosion resistance. The multi-pass laser-cladding layers prepared at laser powers of 2.1 and $2.3 \mathrm{~kW}$ show passive current densities of 0.578 and $0.599 \mu \mathrm{A} / \mathrm{cm}^{2}$, respectively, illustrating better corrosion resistance. In contrast, the passive current densities of the layers prepared at 1.9 and $2.5 \mathrm{~kW}$ are 1.185 and $6.512 \mu \mathrm{A} / \mathrm{cm}^{2}$, respectively, showing poorer corrosion resistance.

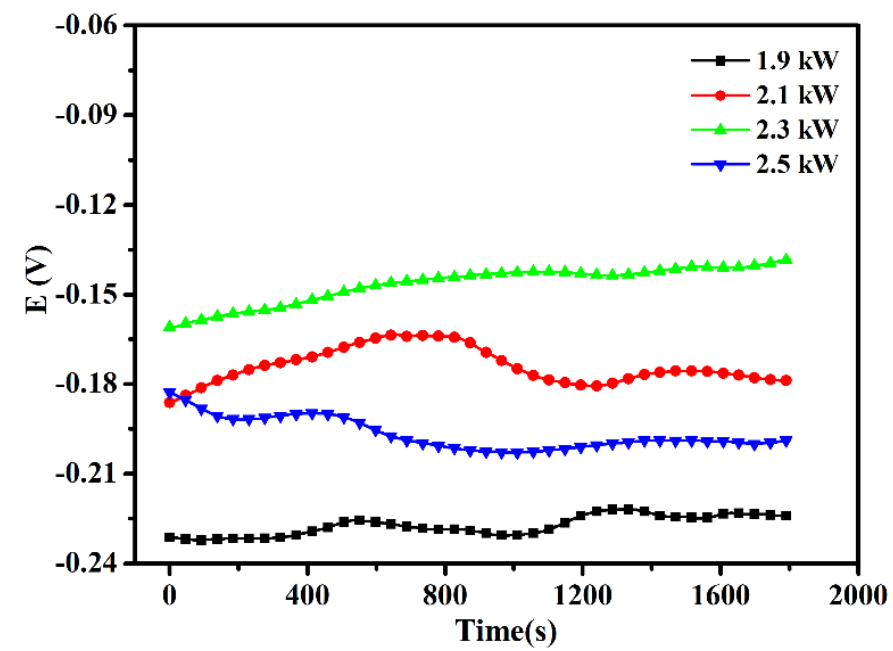

Figure 7. Open-current potentials of the multi-pass laser-cladding layers prepared at laser powers of $1.9,2.1,2.3$, and $2.5 \mathrm{~kW}$.

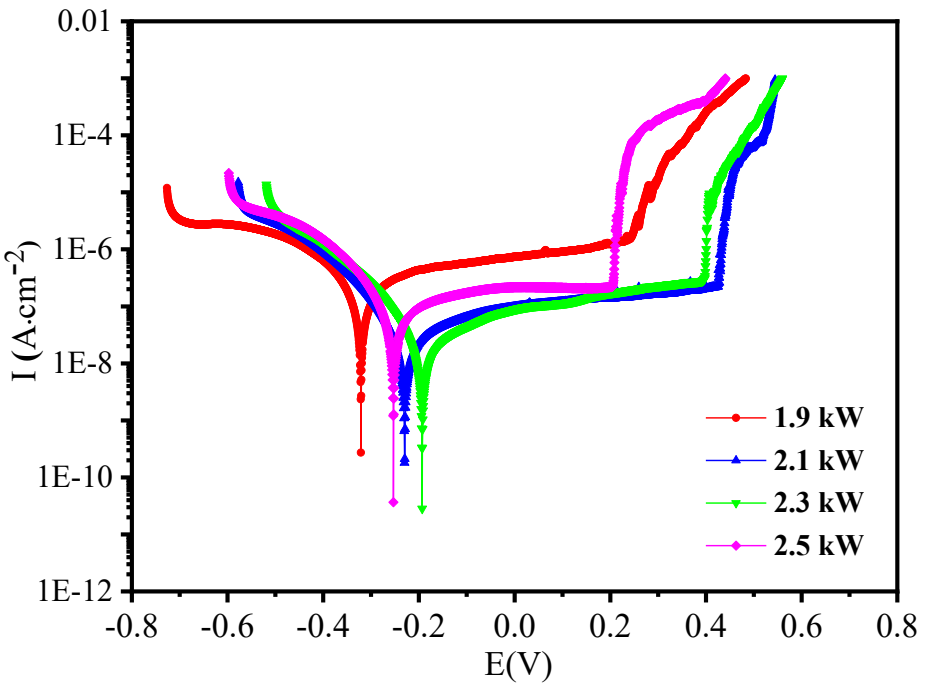

Figure 8. Potentiodynamic polarization curves of the multi-pass laser-cladding layers prepared at laser powers of $1.9,2.1,2.3$, and $2.5 \mathrm{~kW}$ in $3.5 \mathrm{wt} . \% \mathrm{NaCl}$ solution.

Table 3. Fitting parameters of potentiodynamic polarization curves of the multi-pass laser-cladding layers prepared at laser powers of $1.9,2.1,2.3$, and $2.5 \mathrm{kw}$ in $3.5 \mathrm{wt} . \% \mathrm{NaCl}$ solution.

\begin{tabular}{ccccc}
\hline Laser Power $(\mathbf{k W})$ & $\boldsymbol{E}_{\text {corr }}(\mathbf{m V})$ & $\boldsymbol{I}_{\text {corr }}\left(\mu \mathrm{A} / \mathbf{c m}^{2}\right)$ & $\boldsymbol{E}_{\boldsymbol{b}}(\mathbf{m V})$ & $\boldsymbol{i}_{\boldsymbol{p}}{ }^{2}\left(\boldsymbol{\mu A} / \mathbf{c m}^{2}\right)$ \\
\hline Substrate [24] & -709.2 & 2.881 & - & - \\
1.9 & -321.1 & 1.972 & 242.7 & 6.512 \\
2.1 & -230.5 & 0.175 & 424.8 & 0.578 \\
2.3 & -193.2 & 0.119 & 394.2 & 0.599 \\
2.5 & -253.2 & 0.410 & 204.0 & 1.185 \\
\hline
\end{tabular}


Based on synthetic consideration of the above parameters, including OCP, $E_{c o r r}, I_{c o r r}$, $E_{b}$, and $i_{p}^{\prime}$, the corrosion resistance of the multi-pass laser-cladding layer first increases and then decreases with an increase in laser power. The multi-pass laser-cladding layer prepared at $2.3 \mathrm{~kW}$ has the lowest corrosion tendency and the best corrosion resistance. This is mainly because the microstructure of the multi-pass laser-cladding layer prepared at $2.3 \mathrm{~kW}$ is relatively uniform, comprising a large number of equiaxed crystals and a few cellular crystals. Therefore, stable oxide film is formed on the surface, which hinders the invasion of corrosive ions, thus improving its corrosion resistance.

While the solidification structure of the upper area of the interface (region B of track $n+1$ ) of the laser-cladding layer prepared at $1.9 \mathrm{~kW}$ is columnar and dendritic, that of the lower region of the interface (region A of track $n$ ) is composed of fine columnar crystals and a few equiaxed crystals (Figures 4 and 5). The interface between these two kinds of structures is quite obvious, which increases the risk of galvanic corrosion and results in the poor corrosion resistance of the multi-pass laser-cladding layer (Figures 7 and 8). When laser power reaches $2.5 \mathrm{~kW}$, a sufficient molten-pool reaction results in a microstructure of the cladding layer. However the evaporation of alloyed elements is serious, leading to large pores in the microstructure (seen in Figure 6), and ultimately reduces the corrosion resistance of the multi-pass laser-cladding layer. The $\gamma$-Fe phase partially transforms into an $\alpha$-Fe phase with an increase in laser input energy (Figure 3), which may also be one of the factors affecting the corrosion resistance of the laser-cladding layer. However, the corrosion behavior of the $\gamma$-Fe phase and the $\alpha$-Fe phase is quite complicated; it is difficult to determine their contributions to the current case. In addition, the $E_{c o r r}$ and $I_{\text {corr }}$ of the multipass laser-cladding layer prepared at $2.3 \mathrm{~kW}$ are $27 \%(-709.2 \mathrm{mV})$ and $4.1 \%\left(2.881 \mu \mathrm{A} / \mathrm{cm}^{2}\right)$ of Q235 carbon steel, respectively, which is consistent with the electrochemical test results of single-pass laser-cladding layers.

In order to further understand the electrochemical properties of the laser-cladding layers, electrochemical impedance spectroscopy (EIS) tests were carried out in $3.5 \mathrm{wt} \%$ $\mathrm{NaCl}$ solutions. The results are illustrated in Figure 9. The high polarization resistances of the as-prepared laser-cladding layers prove the excellent protection effect of the 2205DSS laser-cladding layers on the substrate. Figure 9a shows that with an increase in laser power, the arc radii of the laser-cladding layers first increase and then decrease. The radius value of the Nyquist plot reflects the magnitude of the corrosion resistance. Obviously, the largest arc radius is that of the multi-pass laser-cladding layer prepared at $2.3 \mathrm{~kW}$, as observed in Figure $9 \mathrm{a}$, indicating its superior corrosion resistance. Two-time constants can be observed in the Bode phase-angle plots of the multi-pass laser-cladding layers (Figure 9b), suggesting that the corrosion of the multi-pass laser-cladding layers is influenced by two dynamic processes due to the presence of chromium-rich passive film on the layer. The time constant at the high-frequency band is attributed to the charge-transfer reaction occurring at the 2205 DSS passive film-solution interface, and the time constant at the low-frequency band represents the properties of the passive film. In addition, Bode phase-angle and impedance modulus $|\mathrm{Z}|$ diagrams also exhibit the same rule as Nyquist diagrams.

The experimental data shown in Figure 9 were fitted by using the equivalent circuit model of $\mathrm{R}(\mathrm{Q}(\mathrm{R}(\mathrm{QR}))$ ) (Figure 10). The detailed fitting data are illustrated in Table 4. Rs is the solution resistance; R1 and CPE1 represent the resistance and capacitance of the 2205 DSS passive film, respectively; Rct reflects charge-transfer resistance; and CPE2 represents the capacitance of the electric double layer [26]. The constant phase-angle element (CPE) is used to represent the capacitance induced by the relaxation of time distribution caused by the heterogeneity and roughness of the surface of the laser-cladding layers [27]. The impedance of the CPE is defined as: $\mathrm{Z}_{\mathrm{CPE}}=1 /\left[\mathrm{Q}(\mathrm{jw})^{\mathrm{n}}\right]$, in which $\mathrm{j}$ is an imaginary number, $\mathrm{w}$ is an angular frequency $(\mathrm{w}=2 \pi \mathrm{f})$, and $\mathrm{n}$ is CPE constant. CPE is regarded as a pure capacitor when $n=1$, while CPE behaves as a resistance when $n=0[28,29]$. 

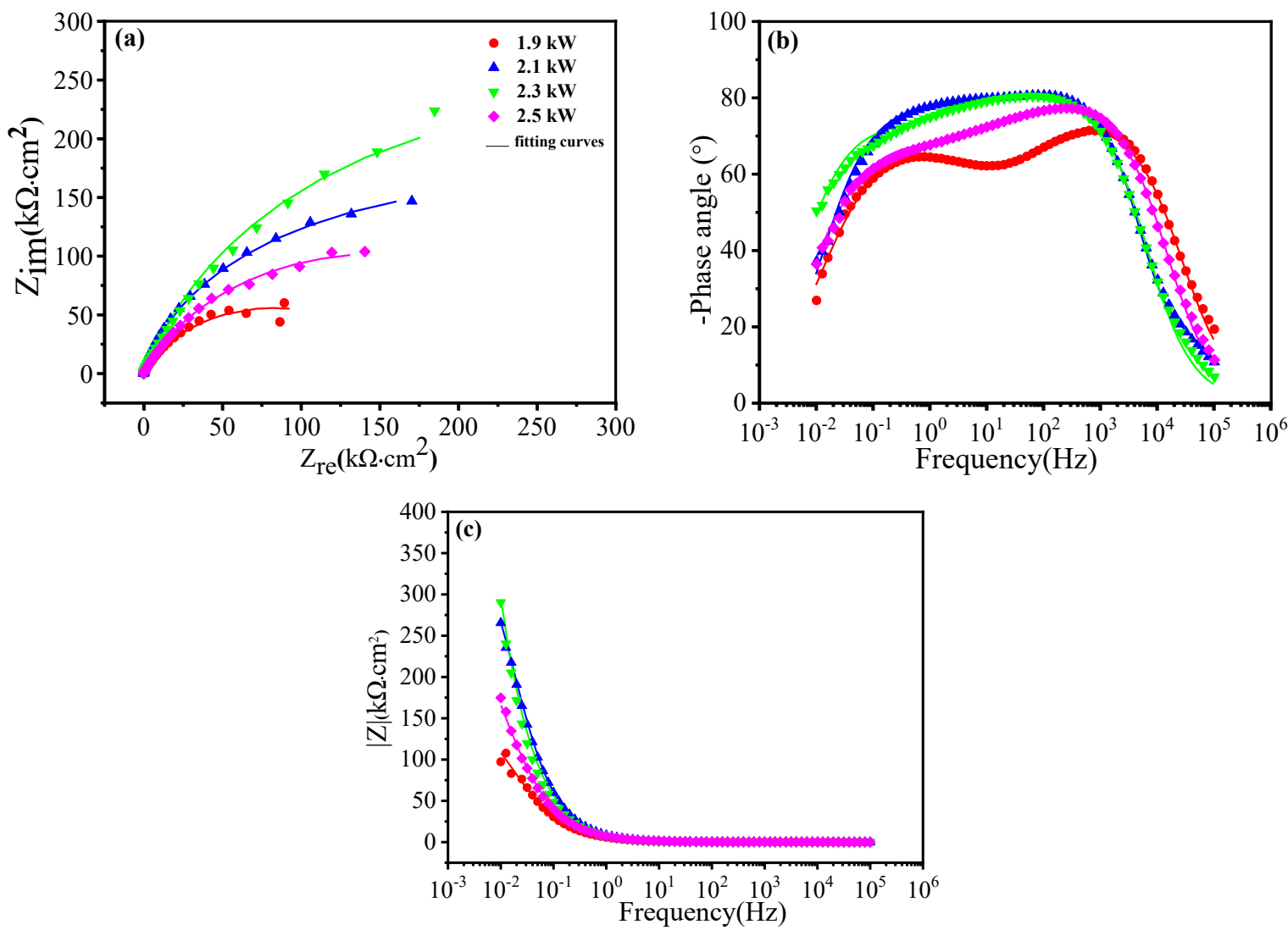

Figure 9. Electrochemical impedance spectra of the multi-pass laser-cladding layers prepared at laser powers of 1.9, 2.1, 2.3, and $2.5 \mathrm{kw}$ in $3.5 \mathrm{wt}$ \% $\mathrm{NaCl}$ solution. (a) Nyquist plots, (b) Bode-phase angle plots, (c) Bode modulus plots.

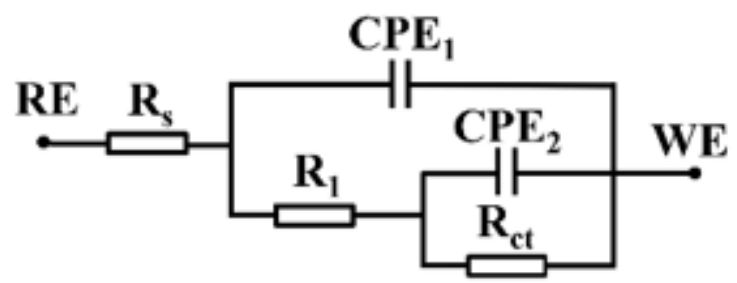

Figure 10. Equivalent circuit model $R(Q(R(Q R)))$ of the fabricated laser-cladding layer when immersed in 3.5 wt. $\% \mathrm{NaCl}$ solution.

Table 4. EIS fitting parameters for equivalent circuit model $\mathrm{R}(\mathrm{Q}(\mathrm{R}(\mathrm{QR})))$ of the multi-pass lasercladding layers prepared at laser powers of $1.9,2.1,2.3$, and $2.5 \mathrm{kw}$ in $3.5 \mathrm{wt} . \% \mathrm{NaCl}$ solution.

\begin{tabular}{ccccccccc}
\hline Fitting Parameters & $\mathbf{R}_{\mathbf{s}}$ & $\mathbf{C P E}_{\mathbf{1}}$ & $\mathbf{n}_{\mathbf{1}}$ & $\mathbf{R}_{\mathbf{1}}$ & $\mathbf{C P E}_{\mathbf{2}}$ & $\mathbf{n}_{\mathbf{2}}$ & $\mathbf{R}_{\mathbf{c t}}$ & $\boldsymbol{\chi}^{\mathbf{2}} \mathbf{( 1 0}^{-\mathbf{4}}$ ) \\
\hline Substrate [24] & 4.879 & 633.8 & 0.814 & - & - & - & 1.587 & 1.64 \\
$1.9 \mathrm{~kW}$ & 2.201 & 17.73 & 0.8421 & 1.329 & 25.83 & 0.7237 & 163.0 & 8.79 \\
$2.1 \mathrm{~kW}$ & 2.402 & 19.53 & 0.8468 & 30.21 & 4.375 & 0.8215 & 372.0 & 5.14 \\
$2.3 \mathrm{~kW}$ & 2.816 & 24.08 & 0.9002 & 49.91 & 9.087 & 0.7434 & 525.3 & 9.09 \\
$2.5 \mathrm{~kW}$ & 2.171 & 19.64 & 0.8787 & 6.333 & 15.69 & 0.6748 & 296.4 & 5.38 \\
\hline
\end{tabular}

Note: Units of $R_{s}, R_{1}, R_{c t}$, and CPE are $\Omega \cdot \mathrm{cm}^{2}, \mathrm{k} \Omega \cdot \mathrm{cm}^{2}, \mathrm{k} \Omega \cdot \mathrm{cm}^{2}$, and $\mu \mathrm{F} \cdot \mathrm{cm}^{-2}$, respectively.

The resistances of the multi-pass laser-cladding layers and their corresponding chargetransfer resistances first increase and then decrease with increasing laser power, reaching their highest values of 49.91 and $525.3 \mathrm{k} \Omega \cdot \mathrm{cm}^{2}$ at a laser power of $2.3 \mathrm{~kW}$, reflecting the best 
corrosion resistance among all the cases. The same conclusion can be drawn based on both PDP and EIS measurements. This is attributed to the fact that there are some directional columnar dendrites and an obvious interface between adjacent tracks in the laser-cladding layers prepared at low laser powers (1.9 and $2.1 \mathrm{~kW}$ ) (Figure 4). A galvanic corrosion microcell may form between coarse grains and the surrounding small grains, resulting in poor corrosion resistance of the multi-pass laser-cladding layers [30]. In contrast, for the case of the multi-pass laser-cladding layer prepared at a laser power of $2.5 \mathrm{~kW}$ (Figure 6), the pores provide more channels for penetration by corrosive substances, resulting in a decrease in corrosion resistance [31]. The multi-pass laser-cladding layer prepared at $2.3 \mathrm{~kW}$, possessing a uniform and fine microstructure, demonstrates the best corrosion resistance among all the cases.

\subsection{Wear-Resistance Analysis of the Laser-Cladding Layers}

Figure 11a shows the variation curve of the friction coefficient of the Q235 carbon steel substrate and the 2205DSS multi-pass laser-cladding layer prepared at a laser power of $2.3 \mathrm{~kW}$ as a function of test time during the friction process. It is found that the friction coefficient of the Q235 carbon steel substrate displays an initial period of rapid change, reaching a maximum value of about 0.75 , and then gradually declines to a steady value of about 0.7 . The friction coefficient of the 2205DSS multi-pass laser-cladding layer prepared at $2.3 \mathrm{~kW}$ exhibits a rapid increase at the initial stage, reaching a maximum value, and fluctuates with time between 0.4 and 0.6 .
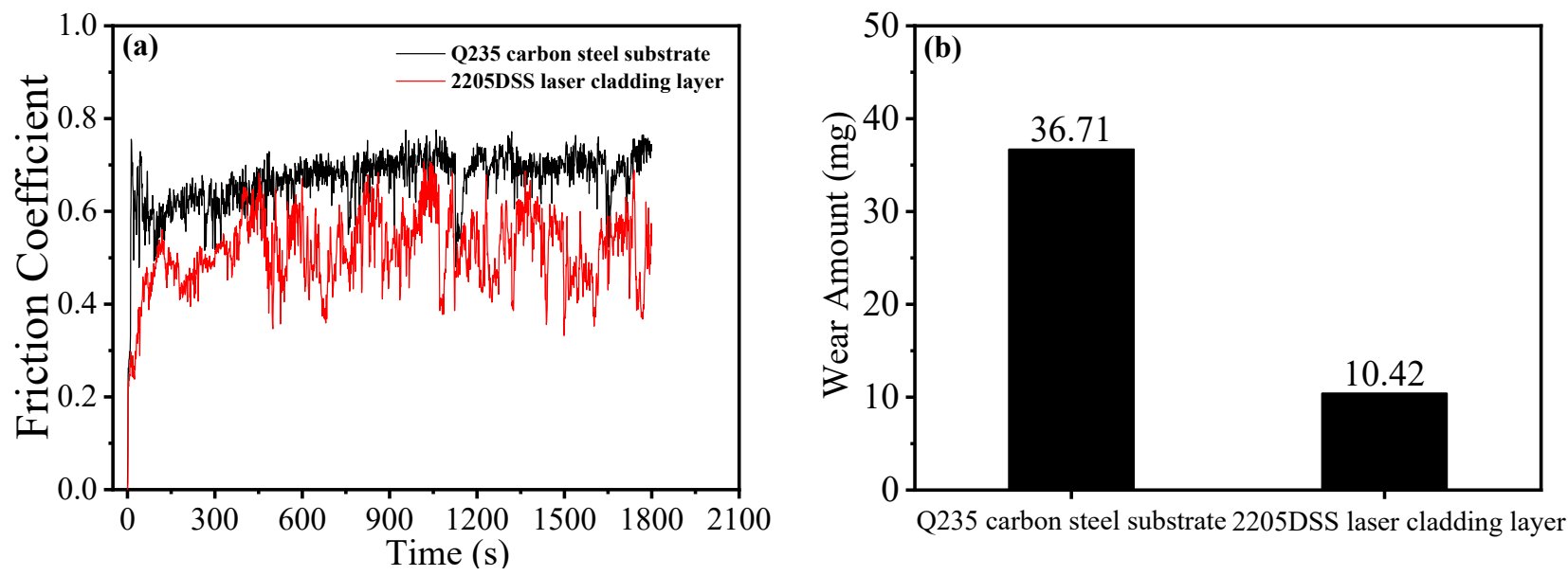

Figure 11. (a) Friction coefficient curves and (b) wear quantity of Q235 carbon steel substrate and stainless steel.

The friction coefficient time dependance curve can be divided into three stages: running-in stage, stable wear stage, and sharp wear stage (destructive wear stage) [32]. Due to the limited contact surface between the standard ring and the multi-pass laser-cladding layer at the initial stage of friction and wear tests, the friction coefficient increases rapidly. With the progress of the friction process, the contact surface gradually increases, and the friction process tends to be stable and enters the stable wear stage. No destructive wear stage is observed in the current friction coefficient time dependance curve. The multi-pass laser-cladding layer has a lower friction coefficient and better wear resistance compared to the Q235 carbon steel.

In addition to the friction coefficient, the wear amounts of the Q235 carbon steel substrate and the multi-pass laser-cladding layer are 36.71 and $10.42 \mathrm{mg}$, respectively, implying the better wear resistance of the multi-pass laser-cladding layer (summarized in Figure 11b).

SEM images of the worn surfaces of the Q235 carbon steel and the multi-pass lasercladding layer prepared at $2.3 \mathrm{~kW}$ are shown in Figure 12a,c, respectively. Figure 12b,d 
presents a magnified view of the rectangular region on the top layer. In Figure 12a,c, debris ripples are found on the wear surface. To make clear the composition of different regions after friction, EDS point scans of the Q235 and the multi-pass laser-cladding layer prepared at $2.3 \mathrm{~kW}$ were also carried out. The scan points are marked in Figure 12b,d, results of which are summarized in Table 5. Three similar positions of the bare Q235 metal/2205DSS multi-pass laser-cladding layer surface caused by friction and the abrasive debris surfaces were selected and point-scanned. Similar results were obtained for each type of surface; therefore, only one result is listed in Table 5.
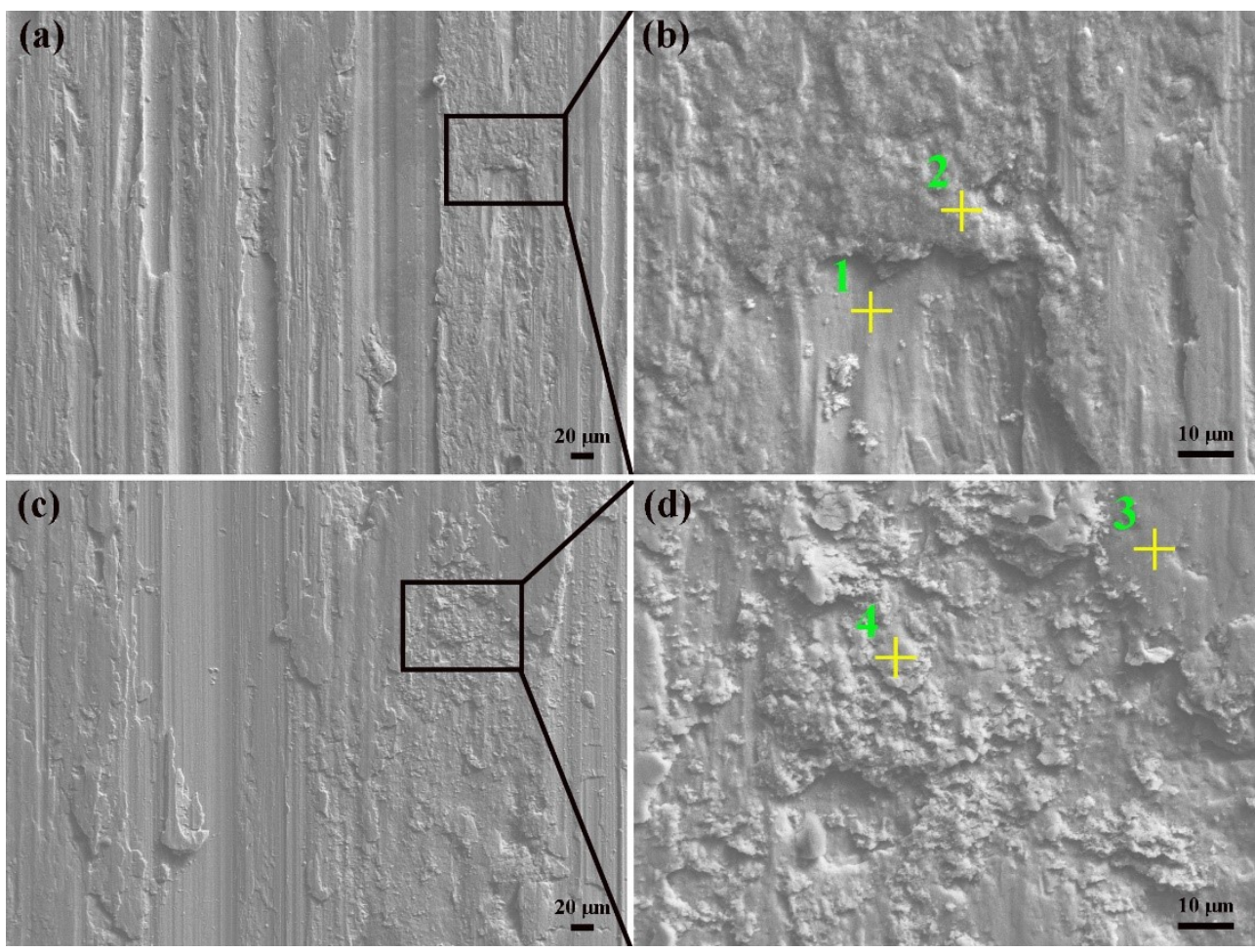

Figure 12. Friction topographies of $Q 235$ carbon steel substrate and 2205DSS laser-cladding layer: (a) Q235 carbon steel substrate surface; (b) enlarged view of Q235 carbon steel substrate surface; (c) 2205 DSS laser-cladding layer surface; (d) enlarged view of 2205 DSS laser-cladding layer surface.

Table 5. Chemical compositions of the friction surfaces of the Q235 carbon steel substrate and the 2205DSS laser-cladding layer (wt.\%).

\begin{tabular}{cccccc}
\hline Position & Cr & Ni & Mo & Si & O \\
\hline 1 & - & - & - & 0.23 & - \\
2 & - & - & - & 0.36 & 18.40 \\
3 & 21.28 & 5.38 & 1.58 & 1.01 & 9.03 \\
4 & 20.51 & 6.09 & 1.35 & 1.02 & 7.39 \\
\hline
\end{tabular}

Obvious plough grooves parallel to the sliding direction can be observed in Figure 12a, accompanied by serious plastic deformation in the surrounding area. This can be attributed to typical abrasive wear mechanisms. GCr15 bearing steel is the grinding material in the friction process. Under the action of abrasive particles, the soft Q235 carbon steel substrate surface goes through plastic deformation and is pushed to both sides of the grinding groove. Grooves or furrows are formed on the material surface as a result of microcutting, pushing, and grinding. The substrate is squeezed to both sides of the groove because the plastic deformation peels off, forming abrasive particles, thus acting as new abrasive particles. The abrasive debris peeled from the Q235 carbon steel substrate, the composition of which was analyzed by EDS, accumulates on the surface. Compared with the composition of the 
bare metal surface (point 1 ) caused by friction, oxygen is detected in the abrasive debris (point 2) due to the oxidation of abrasive debris during the friction process in air.

Furrows and pits can be identified in the friction surface morphology of the multi-pass laser-cladding layer, as illustrated in Figure 12c. This phenomenon can be interpreted as a result of a combination of abrasive wear mechanisms and adhesive wear mechanisms [16]. Portions of the abrasive surface that were not exfoliated due to the pushing and grinding action of abrasive wear are also observed. EDS results of the multi-pass laser-cladding layer exposed by friction (point 3) and abrasive debris (point 4) also indicate the presence of oxygen elements, suggesting that the oxidation process occurs even during the friction-wear process of the multi-pass laser-cladding layer.

In addition to microstructure, oxide film is the other crucial factor affecting the wear resistance of the coatings. The 2205DSS laser-cladding layer contains a large amount of alloy elements, such as $\mathrm{Cr}, \mathrm{Ni}$, and $\mathrm{Mo}$, which can be easily combined with oxygen elements to form an oxide film. The oxide film formed on the laser-cladding layer plays the role of lubricant in the wear process and therefore improves the wear resistance of the multi-pass laser-cladding layer [33]. It should be noted that a decrease in wear speed and abnormal friction sound are also observed during the friction and wear processes of the multi-pass laser-cladding layer due to adhesive wear, resulting in the fluctuation of the friction coefficient of the multi-pass laser-cladding layer within a certain range.

Figure 13 shows the three-dimensional topographies of the friction surfaces of the Q235 carbon steel substrate and the 2205DSS multi-pass laser-cladding layer prepared at $2.3 \mathrm{~kW}$. As can be seen from Figure 13a, the contour of the friction surface of the Q235 carbon steel substrate, with deep and numerous furrows, shows regular ups and downs, among which the deeper blue area is formed after the abrasive particles on the surface of the GCr15 bearing steel plough into the softer Q235 carbon steel substrate, while the shallow red area is caused by the plastic deformation of the substrate on both sides after the abrasive particles are ploughed in.
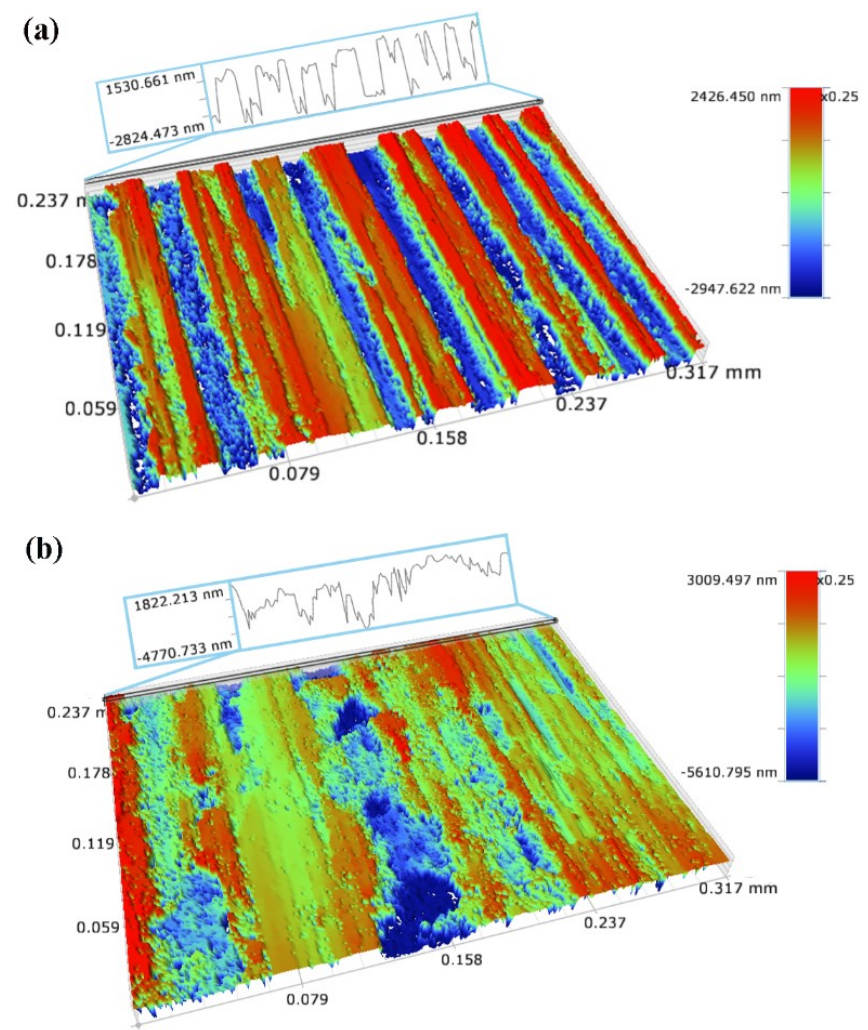

Figure 13. Three-dimensional friction surface topography of (a) Q235 carbon steel substrate and (b) 2205DSS laser-cladding layer. 
The furrows on the surface of the multi-pass laser-cladding layer illustrated in Figure 13b are relatively shallow, whereas more grooves or pits can be identified. The existence of larger and deeper grooves indicates that the damage degree of adhesive wear in the multipass laser-cladding layer is high and that the local surface of the multi-pass laser-cladding layer is glued to the grinding material and then tears. The main factors affecting the adhesive wear of materials are the properties of the two pairs of grinding materials and the working conditions during the wear process.

Based on the above analysis, the wear resistance of the 2205DSS multi-pass laser cladding is better than that of the Q235 carbon steel substrate in terms of friction coefficient and wear quantity. The wear mechanism of the Q235 carbon steel substrate is abrasive wear, while that of the multi-pass laser-cladding layer prepared at $2.3 \mathrm{~kW}$ is a combination of adhesive wear and abrasive wear, accompanied by oxidative wear.

\section{Conclusions}

Based on previous studies of single-pass laser-cladding layers, a 2205DSS multi-pass laser-cladding experiment was carried out on the surface of Q235 carbon steel. The phase composition, microstructure, and corrosion resistance of multi-pass laser-cladding layers prepared at laser powers within the range of $1.9-2.5 \mathrm{~kW}$ were obtained and discussed. Further characterizations, i.e., wear resistance, of the optimized multi-pass laser-cladding layer and the Q235 carbon steel were compared, and the main conclusions are as follows:

(1) Multi-pass laser-cladding layers prepared under selected laser powers in the range of 1.9-2.5 kW possess good surface qualities, and based on macroscopic observation, no obvious cracks are present. The multi-pass laser-cladding layers are composed of $\gamma$-Fe and $\alpha$-Fe phases.

(2) The solidification structure in the upper area of the interface formed between two adjacent tracks at a laser power of $1.9 \mathrm{~kW}$ is columnar and dendritic, whereas that in the lower region of the interface is composed of fine columnar crystals and a few equiaxed crystals. When laser power is increased to 2.3 and $2.5 \mathrm{~kW}$, the microstructure of the upper and lower regions of the adjacent interface is almost the same, comprising a large number of equiaxed crystals and a small number of cellular crystals and showing little difference between adjacent passes.

(3) Based on a synthetical consideration of OCP, $E_{c o r r}, I_{c o r r}, E_{b}$, and $i_{p}^{\prime}$, the corrosion resistance of the multi-pass laser-cladding layer first increases and then decreases with an increase in laser power. The multi-pass laser-cladding layer prepared at $2.3 \mathrm{~kW}$ has the lowest corrosion tendency and the best corrosion resistance, which can be attributed to its uniform structure comprising a large number of equiaxed crystals and a few cellular crystals. The corrosion potential and corrosion-current density of the multi-pass lasercladding layer prepared at $2.3 \mathrm{~kW}$ are 27 and $4.1 \%$ of the carbon steel substrate, respectively, indicating good corrosion resistance.

(4) Friction and wear-resistance tests of the 2205DSS multi-pass laser-cladding layer reveal less abrasion loss and a smaller friction coefficient, the wear behavior of which is greatly improved compared with that of the carbon steel substrate. The plough-groove feature of the friction surface of the carbon steel is obvious, which is a typical abrasive wear mechanism. The appearance of pits and furrows on the friction surface of the multipass laser-cladding layer implies a combined action of adhesive wear and abrasive wear, accompanied by oxidative wear.

\section{Limitations and Future Work}

Laser cladding is widely used in all walks of life because of its low manufacturing cost and short production cycle. However, its low cladding efficiency has limited its application in large components. On the other hand, to reduce stress in the substrate, strengthening the microstructure organization by adjusting laser-cladding parameters or adding rare earth elements, as well as adding titanium carbide or other hard ceramic particles to further 
improve its wearability so as to satisfy specific application requirements, are all promising directions worthy of further research.

Author Contributions: Conceptualization, F.H.; methodology, F.H. and E.L.; software, F.H., E.L., Y.Q and Q.W.; validation, F.H., Q.W. and E.L.; formal analysis, F.H. and E.L.; investigation, F.H. and Y.Q.; resources, F.H. and Y.J.; data curation, F.H., E.L. and Y.Q.; writing-original draft preparation, F.H. and E.L.; writing-review and editing, F.H. and E.L.; visualization, F.H. and E.L.; supervision, L.W. and Y.J.; project administration, F.H., Y.J. and H.C.; funding acquisition, Y.J. All authors have read and agreed to the published version of the manuscript.

Funding: This research was funded by Innovation Group Project of Southern Marine Science and Engineering Guangdong Laboratory (Zhuhai), Grant No.311021013. The authors are also grateful for the support from China Nuclear Power Engineering Co., Ltd. (No.KY1672) and the 111 Project (Grant No.B12012) in China for promoting international exchange.

Institutional Review Board Statement: Not applicable.

Informed Consent Statement: Not applicable.

Data Availability Statement: Not applicable.

Acknowledgments: The authors sincerely thank Jiaoxi Yang of Beijing University of Technology for laser-cladding sample preparation. Many thanks to Lei Yang in Yang's lab for assistance with experiments and valuable suggestions.

Conflicts of Interest: The authors declare no conflict of interest.

\section{References}

1. Zhang, C.Q.; Chen, Y.; Yu, J.; Zhou, J.; Li, L.; Wang, Z. Influence of high-frequency micro-forging on microstructure and properties of 304 stainless steel fabricated by laser rapid prototyping. Steel Res. Int. 2013, 84, 870-877. [CrossRef]

2. Khan, H.I.; Zhang, N.; Zhu, Z.; Jiang, D.; Asif, T.; Xu, H. Behavior and susceptibility to stress corrosion cracking of a nickel-based alloy in superheated steam and supercritical water. Corros. Mater. 2019, 70, 48-56. [CrossRef]

3. Li, W.; Xu, P.; Wang, Y.; Zou, Y.; Gong, H.; Lu, F. Laser synthesis and microstructure of micro- and nano-structured WC reinforced Co-based cladding layers on titanium alloy. J. Alloys Compd. 2018, 749, 10-22. [CrossRef]

4. Baidridge, T.; Poling, G.; Foroozmehr, E.; Kovacevic, R.; Metz, T.; Kadekar, V.; Gupta, M.C. Laser cladding of Inconel 690 on Inconel 600 superalloy for corrosion protection in nuclear applications. Opt. Laser Technol. 2013, 51, 180-184. [CrossRef]

5. Núñez, Y.; Mafra, M.; Morales, R.E.; Borges, P.C.; Pintaude, G. The effect of plasma nitriding on the synergism between wear and corrosion of SAF 2205 duplex stainless steel. Ind. Lubr. Tribol. 2020, 72, 1117-1122. [CrossRef]

6. Zhou, Y.; Engelberg, D.L. Fast testing of ambient temperature pitting corrosion in type 2205 duplex stainless steel by bipolar electrochemistry experiments. Electrochem. Commun. 2020, 117, 106779. [CrossRef]

7. Zhang, Z.; Farahmand, P.; Kovacevic, R. Laser cladding of 420 stainless steel with molybdenum on mild steel A36 by a high power direct diode laser. Mater. Des. 2016, 109, 686-699. [CrossRef]

8. Pala, Z.; Bai, M.; Lukac, F.; Hussain, T. Laser clad and HVOF-sprayed stellite 6 coating in chlorine-rich environment with KCl at $700{ }^{\circ}$ C. Oxid. Met. 2017, 88, 749-771. [CrossRef]

9. Zhao, J.; Gao, Q.; Wang, H.; Shu, F.; Zhao, H.; He, W.; Yu, Z. Microstructure and mechanical properties of Co-based alloy coatings fabricated by laser cladding and plasma arc spray welding. J. Alloys Compd. 2019, 785, 846-854. [CrossRef]

10. Singh, D.; Gatey, A.M.; Devan, R.S.; Antunes, V.; Alvarez, F.; Figueroa, C.A.; Joshi, A.A.; Hosmani, S.S. Surface treatment response of AISI 2205 and AISI 304L steels: SMAT and plasma-nitriding. Surf. Eng. 2019, 35, 205-215. [CrossRef]

11. Cheikh, H.E.; Courant, B.; Branchu, S.; Huang, X.W.; Hascoët, J.Y.; Guillén, R. Direct laser fabrication process with coaxial powder projection of 316L steel. Geometrical characteristics and microstructure characterization of wall structures. Opt. Laser Eng. 2012, 50, 1779-1784. [CrossRef]

12. Rashid, R.A.R.; Abaspour, S.; Palanisamy, S.; Matthews, N.; Dargusch, M.S. Metallurgical and geometrical characterisation of the 316L stainless steel clad deposited on a mild steel substrate. Surf. Coat. Technol. 2017, 327, 174-184. [CrossRef]

13. Liu, J.; Li, J.; Cheng, X.; Wang, H. Microstructures and tensile properties of laser cladded AerMet100 steel coating on $300 \mathrm{M}$ steel. J. Mater. Sci. Technol. 2018, 34, 643-652. [CrossRef]

14. Xu, P.; Lin, C.; Zhou, C.; Yi, X. Wear and corrosion resistance of laser cladding AISI 304 stainless steel/ $\mathrm{Al}_{2} \mathrm{O}_{3}$ composite coatings. Surf. Coat. Technol. 2014, 238, 9-14. [CrossRef]

15. Wen, J.H.; Zhang, L.J.; Ning, J.; Xue, F.; Lei, X.W.; Zhang, J.X.; Na, S.J. Laser additively manufactured intensive dual-phase steels and their microstructures, properties and corrosion resistance. Mater. Des. 2020, 192, 108710. [CrossRef]

16. Sui, Y.; Yang, F.; Qin, G.; Ao, Z.; Liu, Y.; Wang, Y. Microstructure and wear resistance of laser-cladded Ni-based composite coatings on downhole tools. J. Mater. Process. Technol. 2018, 252, 217-224. [CrossRef] 
17. Tshilwane, N.N.; van der Merwe, J.W. Stress corrosion cracking of laser alloyed 304L stainless steel with Ru in hot chloride solution. Surf. Coat. Technol. 2018, 347, 414-419. [CrossRef]

18. Zhao, G.M.; Wang, K.L. Effect of $\mathrm{La}_{2} \mathrm{O}_{3}$ on corrosion resistance of laser clad ferrite-based alloy coatings. Corros. Sci. 2006, 48 , 273-284. [CrossRef]

19. Zhang, H.; Zou, Y.; Zou, Z.; Shi, C. Effects of $\mathrm{CeO}_{2}$ on microstructure and corrosion resistance of TiC-VC reinforced Fe-based laser cladding layers. J. Rare Earths 2014, 32, 1095-1100. [CrossRef]

20. Wu, Q.; Zhong, N.; Liu, B.; Fan, C.; Li, W.; Yin, Y. Microstructure and corrosion behaviour of laser-clad TiC $-\mathrm{Cr}_{7} \mathrm{C}_{3}-\mathrm{CNTs}_{\mathrm{N}} \mathrm{Cermet}$ coating on 304 stainless steel substrate. Corros. Eng. Sci. Technol. 2015, 51, 136-145. [CrossRef]

21. Papula, S.; Song, M.S.; Pateras, A.; Chen, X.B.; Brandt, M.; Easton, M.; Yagodzinskyy, Y.; Virkkunen, I.; Haenninen, H. Selective laser melting of duplex stainless steel 2205: Effect of post-processing heat treatment on microstructure, mechanical properties, and corrosion resistance. Materials 2019, 12, 2468. [CrossRef]

22. Geenen, K.; Roettger, A.; Theisen, W. Corrosion behavior of 316L austenitic steel processed by selective laser melting, hot-isostatic pressing, and casting. Corros. Mater. 2017, 68, 764-775. [CrossRef]

23. Pardo, A.; Merino, M.C.; Coy, A.E.; Viejo, F.; Arrabal, R.; Matykina, E. Pitting corrosion behaviour of austenitic stainless steels-combining effects of Mn and Mo additions. Corros. Sci. 2008, 50, 1796-1806. [CrossRef]

24. Liu, E.; Huang, F.; Bao, F.; Xue, Y.; Wang, H.; Jin, Y. Microstructure and electrochemical corrosion Behaviors of Laser-Cladded 2205 Duplex Stainless Steel. Steel Res. Int. 2020, 91, 1900456. [CrossRef]

25. Song, L.; Zeng, G.; Xiao, H.; Xiao, X.; Li, S. Repair of 304 stainless steel by laser cladding with 316L stainless steel powders followed by laser surface alloying with WC powders. J. Manuf. Process. 2016, 24, 116-124. [CrossRef]

26. Yang, X.; Du, C.; Wan, H.; Liu, Z.; Li, X. Influence of sulfides on the passivation behavior of titanium alloy TA2 in simulated seawater environments. Appl. Surf. Sci. 2018, 458, 198-209. [CrossRef]

27. Huang, J.; Liu, S.; Wu, L.; Yu, S.; Yu, X.; Yuan, W.; Liao, Y.; Fan, D. The microstructures and corrosion behavior of cladding layer on Ti-6Al-4V alloy using arc deposition with $\mathrm{Ar}$ and $\mathrm{CO}_{2}$ mixed shield gas. J. Alloys Compd. 2020, 857, 157557. [CrossRef]

28. Jiang, P.; Lin, L.; Fan, Z.; Xiang, D.; Lei, R.; Lin, C. Electrochemical construction of micro-nano spongelike structure on titanium substrate for enhancing corrosion resistance and bioactivity. Electrochim. Acta 2013, 107, 16-25. [CrossRef]

29. Fattah-Alhosseini, A.; Ansaria, A.R.; Mazaheri, Y.; Keshavarz, M.K. Effect of immersion time on the passive and electrochemical response of annealed and nanograined commercial pure titanium in Ringer's physiological solution at $37^{\circ} \mathrm{C}$. Mater. Sci. Eng. C 2017, 71, 771-779. [CrossRef]

30. Wei, J.; Dong, J.; Zhou, Y.; He, X.; Wang, C.; Ke, W. Influence of the secondary phase on micro galvanic corrosion of low carbon bainitic steel in $\mathrm{NaCl}$ solution. Mater. Charact. 2018, 139, 401-410. [CrossRef]

31. Xie, F.; He, X.; Cao, S.; Mei, M.; Qu, X. Influence of pore characteristics on microstructure, mechanical properties and corrosion resistance of selective laser sintered porous Ti-Mo alloys for biomedical applications. Electrochim. Acta 2013, 105, 121-129. [CrossRef]

32. Lei, J.; Shi, C.; Zhou, S.; Gu, Z.; Zhang, L.C. Enhanced corrosion and wear resistance properties of carbon fiber reinforced Ni-based composite coating by laser cladding. Surf. Coat. Technol. 2018, 334, 274-285. [CrossRef]

33. Yilmaz, H.; Sadeler, R. Impact wear behavior of ball burnished 316L stainless steel. Surf. Coat. Technol. 2019, 363, 369-378. [CrossRef] 